\title{
Design of Parabolic Leaf Spring Based on FEA and Experimental Result
}

\author{
Sudheer Omprakash Salunke ${ }^{1}$ \\ Dr. D.Y. Patil School of Engineering \& Technology, Pune, India ${ }^{1}$
}

\begin{abstract}
Suspension is one of the main system in vehicle, which gives more comfort to passengers. There are many causes behind parabolic leaf spring failure like improper eye end design, inadequate thickness, maximum stresses in leaves. In any leaf spring, stresses are maximum at U-bolt clamp position and both end eye. In leaf spring, there is large deflection due to uneven loading of bump \& rebound. The stress may occur at center flat distance and over the span of leaf spring. Usually working stresses in parabolic leaf spring are generally evaluated by using testing of spring with load deflection. Stress is evaluated at unclamped position for full-length leaves of entire leaf spring. It is seen that the actual bending stress at the fixed end calculated by testing is 5-6\% more in comparison with modified leaf spring. Bending stress occur away from the flat length of the specified area of the designed parabolic leaf spring. The finite element method by using ABAQUS is applied as a method of analysis to examine the stress distribution for each leaf gives formatting instructions for authors preparing papers for publication in the Proceedings of an International Journal. The authors must follow the instructions given in the document for the papers to be published. You can use this document as both an instruction set and as a template into which you can type your own text.
\end{abstract}

Keywords: Parabolic leaf spring, FEA, CAD, SAE, CAE

\section{INTRODUCTION}

Suspension is one of the main system in vehicle which gives more comfort to passengers. There are many causes behind parabolic leaf spring failure like improper eye end design, inadequate thickness, maximum stresses in leaves. In any leaf spring, stresses are maximum at U-bolt clamp position and both end eye. In leaf spring, there is large deflection due to uneven loading of bump \& rebound. The stress may occur at center flat distance and over the span of leaf spring. Usually working stresses in parabolic leaf spring are generally evaluated by using testing of spring with load deflection. Stress is evaluated at unclamped position for full length leaves of entire leaf spring. It is seen that the actual bending stress at the fixed end calculated by testing is 5-6\% more in comparison with modified leaf spring. Bending stress occur away from the flat length of the specified area of the designed parabolic leaf spring. The finite element method by using ABAQUS is applied as a method of analysis to examine the stress distribution for each leaf.

\section{LITERATURE REVIEW}

In below literature survey, author has explained about two stage leaf spring. Srinivas Kurna and Ruchik Tank (10) Examined through Finite Element Analysis route, Correlate Rig result with Finite Element Analysis (FEA) simulation of multi-stage Leaf Spring Suspension. Correlations have been achieved in both stress and stiffness at strain gauge locations between Computer Aided Engineering (CAE) results and rig test. Correlation has helped in cost of running the rig for failure prediction and reducing product design time. Thus, by using soft validation this process has indirectly reduced the cost. In engineering field CAE still there have been many advances and widely used, physical testing is still used in subsystems as a final confirmation. There is another fact virtual analysis cannot predict in complex assemblies of all variables, therefore the CAE validation results is very important. Correlations have been achieved in both Stress at measured locations between the Rig test and spring rate and CAE results.

Dr. D.V. Bhope, R. B. Charde (12) have investigated analytical equations not able to give the maximum stress values in a master leaf it is useful but it's away from the support to know the values of maximum stress at the support, but to determine the variation in the stresses at the point away from the support experimental technique or finite element method should be used. In present case the stresses on master leaf cannot follow cantilever beam theory but when one extra full length leaves are added to the assembly this theory is validated graduated length leaves.

N.Anu Radha, C.Sailaja, (13) the development of composite leaf spring can be adoptable in place of conventional steel spring, since it is having some tremendous advantage. This project analysed that composites can be used in place of steels for designing leaf springs to reduce weight and improved performance. 


\title{
International Advanced Research Journal in Science, Engineering and Technology
}

\author{
Vol. 5, Issue 10, October 2018
}

\section{PROBLEM STATEMENT AND OBJECTIVE}

Today leaf spring suspension commonly used in light commercial and passenger vehicles. Suspension components Spring, Bushes, fails in within warranty period, it cause cost to auto makers \& vehicle also degrade the ride quality. The aim of this project is to improve leaf spring suspension design so that automakers face minimum warranty \& failures issues with good ride $\&$ handling. Identify some of the problem which generally occurs in case of leaf spring. The usual steel leaf spring has various problems identified which are listed as follow:

a) Maximum deformation: because of continuous running of the vehicle there is a declination in the level of soothed offered by the spring.

b) Low strength: It is observed that the leaf springs be likely to break and deteriorate at the eye end segment which is extremely near to the shackle and at the middle.

c) High weight: The usual steel leaf spring having more weight, which additionally influences the fuel efficiency.

d) Analysis of failure either

e) Design problem

f) Handling Problem

g) Incorrect design validation plan

h) Failure of analysis by using CAE

i) Propose of new leaf spring design with CAE Validation and installation of bushes.

\section{DESIGN METHODOLOGIES}

The main objective of this paper is

1) Experimental Physical testing: to evaluate stress on universal testing machine by using load deflection testing of leaf spring

2) Finite Element Analysis (FEA) simulation of multi-stage Leaf Spring Suspension with existing assembly

3) Design modification in existing Leaf spring and again FEA result follows as modified. Simple verification and reduction in design time. Load deflection of this based correlation methodology will help in two stage of leaf spring design which load rate characteristics are easier than constant rate of leaf spring. This stress evaluation with load deflection test is challenging task, in validation dynamic and static friction will play key role in the suspension system. This methodology developed primarily for parabolic leaf spring \& then used where in leaf spring different types of stages. Every design validated thru physical validation for reliable and durable to prove on vehicle test condition. One more is FEA, by FEA calculation also can prove the component durable, load sustainable or not, through controlled design process only these studies were carried out. These models using real differences, measured manufacturing differences and comparison of the test results. From this load deflection test primary output obtained and leaf string stresses by mathematical calculation. Literature survey for similar category vehicle and suspension system available with competitor's market survey for overall suspension with respect to type of vehicle understanding the use of software tools needed for the project. Design and analysis of parabolic leaf spring investigations for modularity and interchange ability of components.

\section{EXPERIMENTAL EVALUATION}

Actual spring is considered under static loading condition in experimental verification, by using the load deflection technique on universal testing machine the stress evaluation of leaf spring is carried out, for load deflection testing this testing fixture is developed. Load applied on spring at inverted position it is equivalent to vehicle load which considering vehicle rear axle weight.

A. Existing spring in $\mathrm{CAD}$

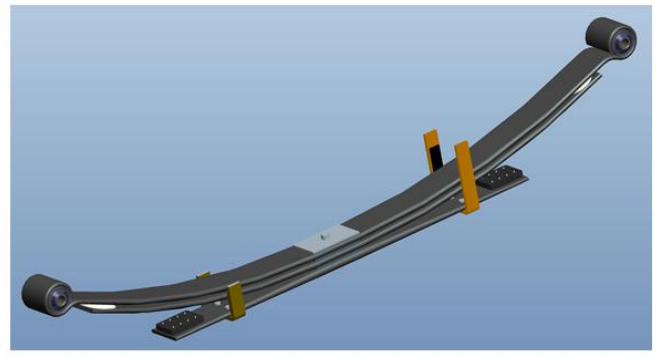

Fig. 1 Existing design 


\section{International Advanced Research Journal in Science, Engineering and Technology}

Vol. 5, Issue 10, October 2018

The leaf spring model is generated in Pro-E. At initial stage of modelling journal is not placed at origin. Its origin has given some random offset by putting values at $\mathrm{X}$ and $\mathrm{Y}$ coordinates. The $\mathrm{X}$ and $\mathrm{Y}$ coordinates of origin are considered for parametric modelling design.

B. Experimental set up for load deflection test

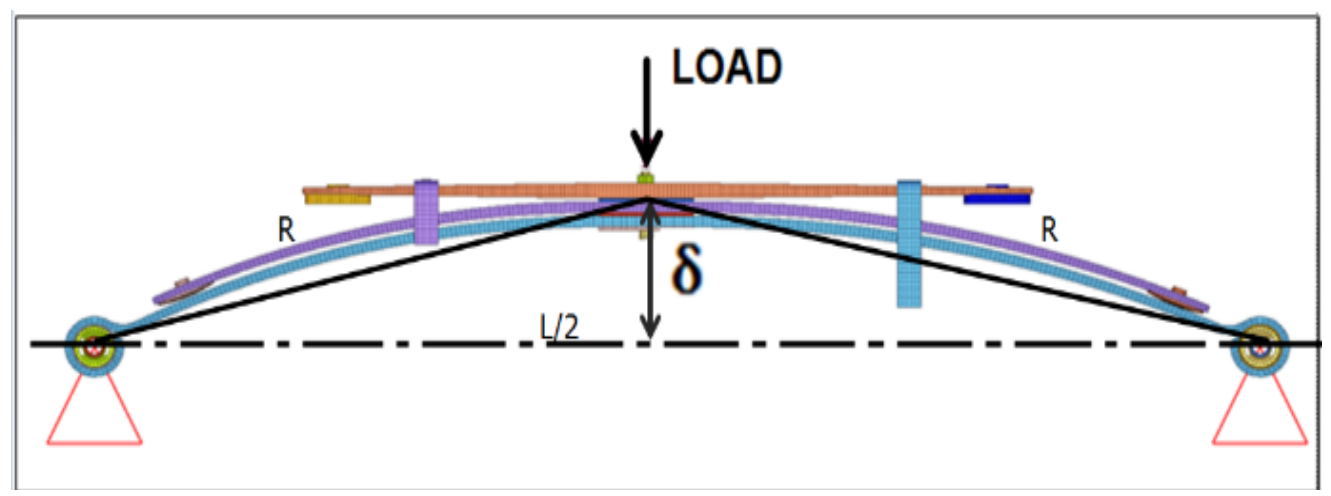

Fig. 2 Experimental Setup in CAD

For experimental analysis using three ranges of leaves in leaf spring assembly. As the leaf spring is unsymmetrical and hence load test carried on parabolic leaf spring. Heavy base is bolted by the complete assembly. The load pan is clamped at end, i.e. on eye. The load is applied on inverted position of spring. The complete setup of experimental is shown in fig no. 3

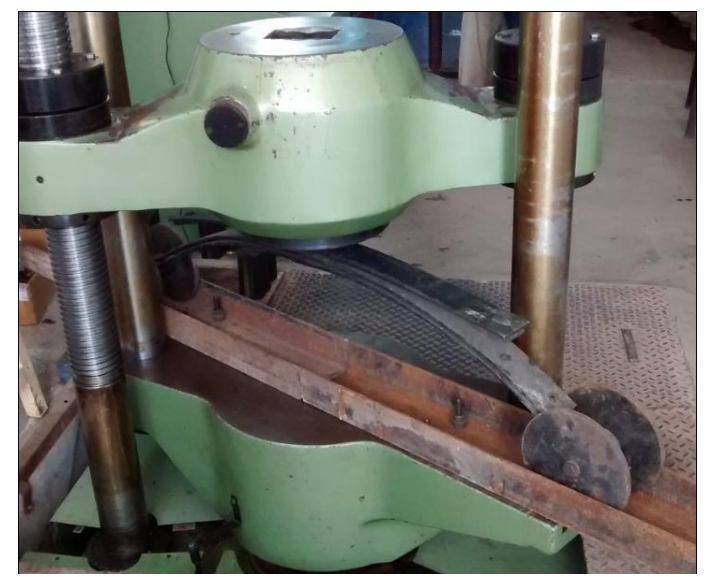

Fig. 3 Experimental Setup

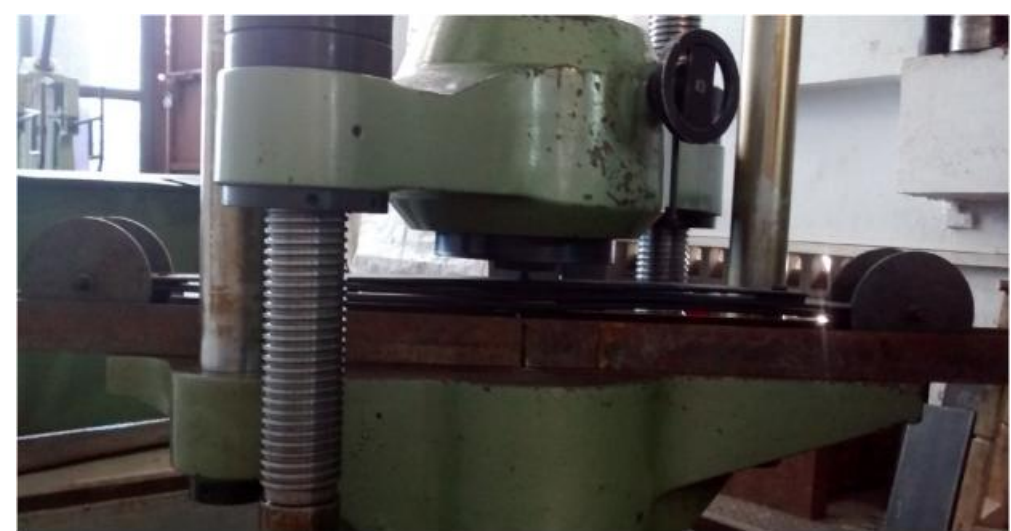

Fig. 4 Experimental Setup

A static load is applied and the load and deflection observed values by this testing machine. A graph shown in Figure 5 is plotted between load and deflection 


\section{International Advanced Research Journal in Science, Engineering and Technology}

Vol. 5, Issue 10, October 2018

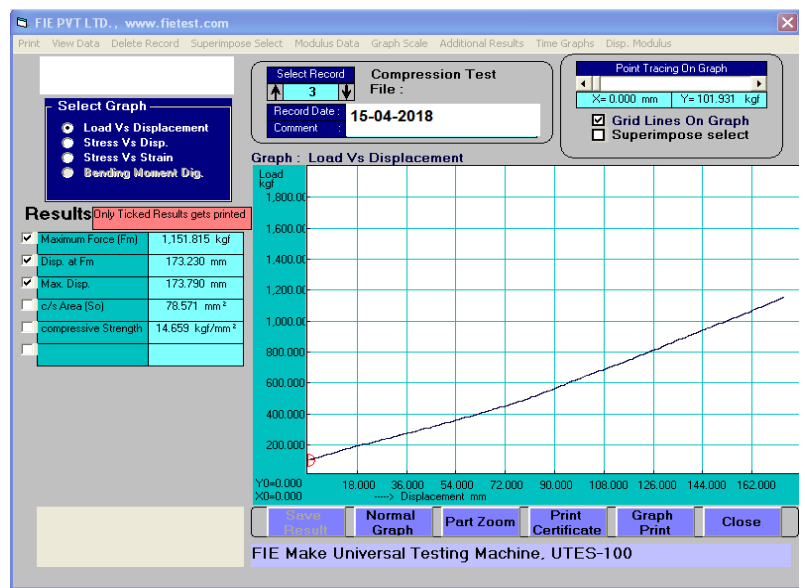

Fig. 5 Load-Deflection Curve

C. Static load: All the nodes associated with the center bolt in this caseload are equally distributed. The load is applied along by direction. To apply load, bolt hole and consequently the nodes associated with it, selecting the circumference is also necessary and it is necessary to understand the number of nodes associated with the circumference of the bolt hole, because the applied load need to divide with the number of nodes associated with the circumference of the center bolt. Step first is under the static loading the FEA was to calculate the spring. This loading case indicated that the stress is equally distributed in the static loading. Determined static load was from the axle mass of the vehicle. Mass distribution of the axle for the single spring in the rear axle was $1150 \mathrm{~kg}$. Stress distribution is shown in Figure 5 . The spring displacement is shown in Figure 4. In the loading situation the spring is almost straight. The finite element analysis of multi leaf spring is performed using Abaqus workbench. The multi leaf spring of conventional steel bending stress and deflection showing under load is shown in figure-4 and Figue-5. From Figure 4, it is obvious that maximum stress developed at the eye sections inner side i.e. the red colour indicates maximum stress, because the constraints applied at the interior of the eyes. Therefore, eyes are witnessed to maximum stress; care must be taken in eye design, fabrication and material selection. The material should have good ductility, resilience and toughness to avoid sudden fracture. That's the reason factor of safety must be increased near the eye. The same procedure taken out for hybrid leaf springs, composite leaf springs, by changing the material properties of the corresponding materials.

\section{4. TESTING CALCULATIONS}

Testing data

Deflection $\delta=173.23 \mathrm{~mm}$ (From Fig .2)

By bending equation

R-bend radius

$$
\frac{E}{R}=\frac{\sigma}{y}
$$

By Pythagoras theorem

$L=(1260-100) m m \quad$ (Effective length)

$$
R^{2}=\left(\frac{L}{2}\right)^{2}+(R-\delta)^{2}
$$

Assumption E steel $=200 \mathrm{GPa}$

$$
\begin{gathered}
L=1.16 \mathrm{~mm} \\
\therefore 2 R \boldsymbol{\delta}=\left(\frac{L}{2}\right)^{2}+\delta^{2} \\
R=1.0589 \mathrm{~m}
\end{gathered}
$$

$$
\begin{gathered}
\frac{E}{R}=\frac{\sigma}{t / 2} \\
\sigma=\frac{E}{R} \times \frac{t}{2} \\
=\frac{200 \times 10^{3}}{1.0589} \times \frac{0.013}{2} \\
\sigma_{\text {testing }}=\mathbf{1 2 2 7 . 7 M P a}
\end{gathered}
$$




\section{International Advanced Research Journal in Science, Engineering and Technology}

Vol. 5, Issue 10, October 2018

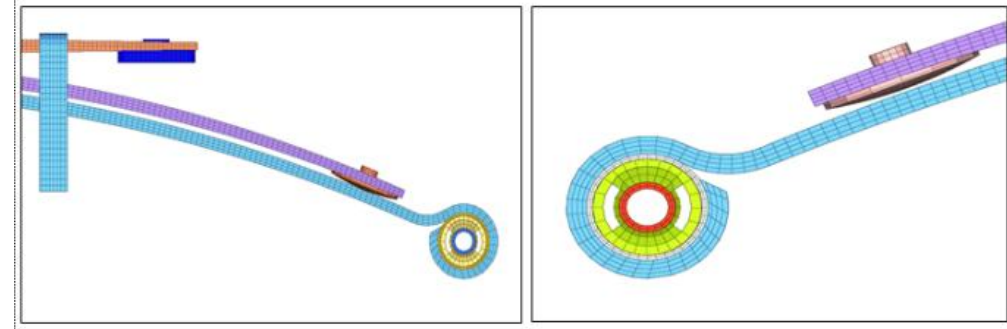

Fig. 6 Existing parabolic leaf spring design

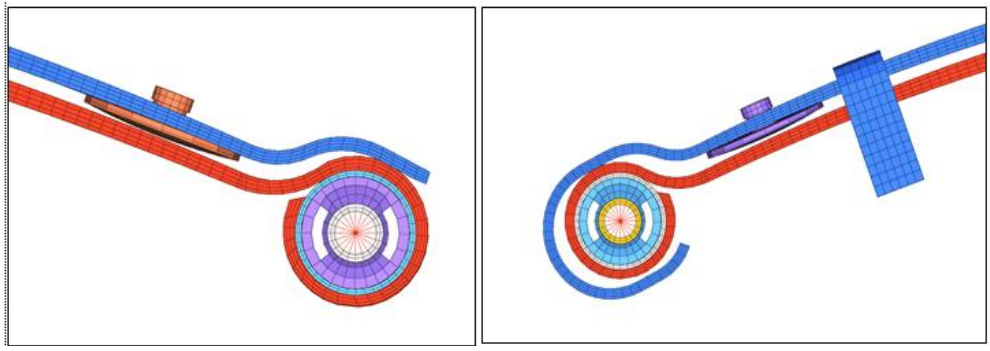

Fig. 7 Modified parabolic leaf spring design

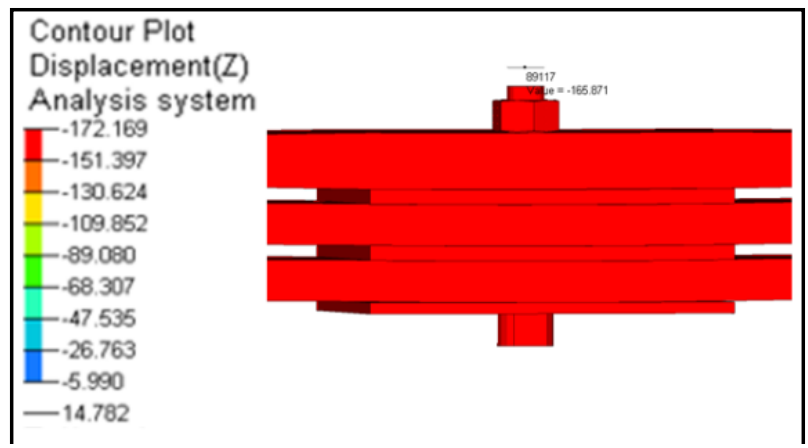

Fig. 8 Existing Parabolic leaf spring Displacement distributions maximum load.

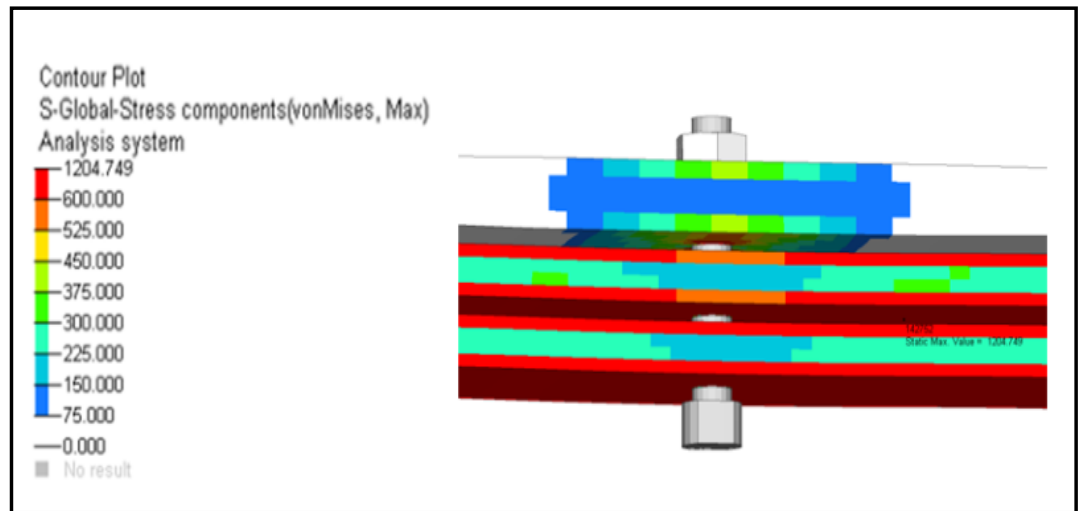

Fig. 9 Location of maximum stress in parabolic leaf spring

Figure 8 and figure 9 shown the existing results in which the more stresses occur at center flat area.

As compare to existing leaf spring changes in modified leaf spring:

- $\quad$ Spring Thickness

- Type of eye

- Position of Friction pad

- Stack Thickness

- Spacer plates

- Position of rebound clamp and front clamp 


\section{International Advanced Research Journal in Science, Engineering and Technology}

Vol. 5, Issue 10, October 2018

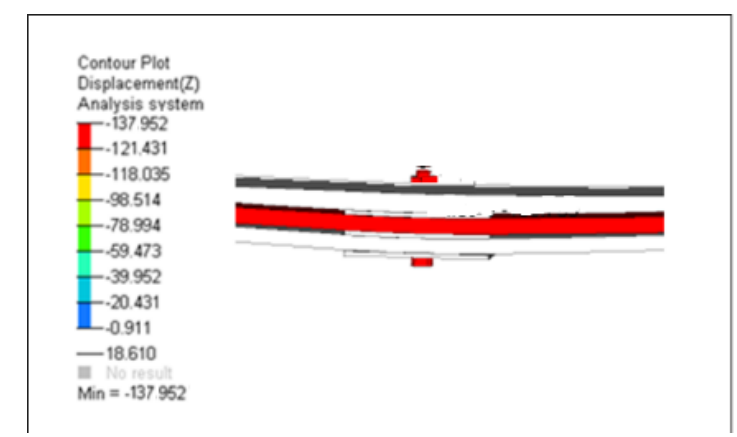

Fig.10 Modified Parabolic leaf spring displacement distributions maximum load

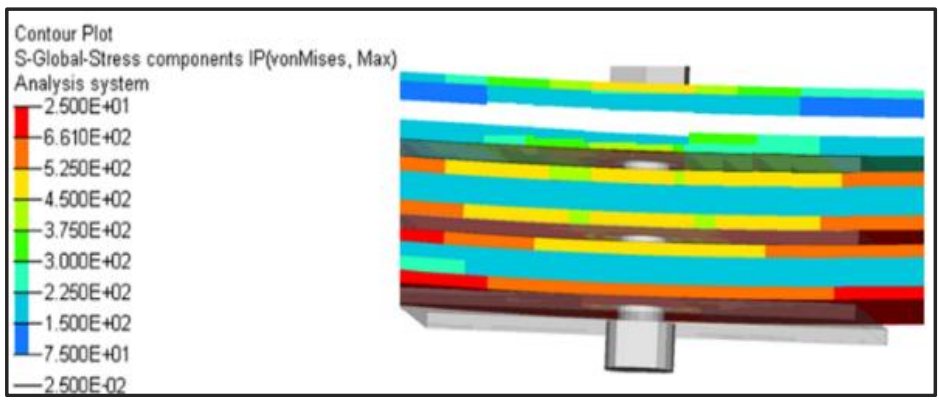

Fig. 11 Modified Parabolic leaf spring Location of maximum stress in parabolic leaf spring

A. Comparison of properties for existing and modified parabolic leaf spring

The main object of the project was to determine the effect of improvement in spring's structure. The force in the direction of the z-axis did not produce any displacement to the spring in the FEA. Magnitude of the force was quite small in the dynamic simulation. FEA did not shown any difference between the unclamped and clamped spring because the stress was created from forces in $\mathrm{y}$ and $\mathrm{x}$-axis. Magnitude of the torque moment over the $\mathrm{x}$-axis was also quite small in the dynamic simulation. Results for the examination were defined from the static loading, normal driving and from curve driving. Deviation between experimental and theoretical result in normal driving stress was $23 \%$ and in curve drive $8 \%$. Errors between results are products from simplifications done in FEA and from difference between simulation and measurement environments. The deviation in static stress values is quite high. Explanation for this spring's initial position is different from in the FEA. In the FEA, the deformation of the spring is similar to ideal case. Figure 10 shows the deformation of the spring under the vehicle. This figure notified that the spring is twisted to the curve in static loading and it creates high static stress to the examination point. The deviation between results can be considerate acceptable. The deflection and stress values of existing leaf spring based on load deflection test values are 184.23 and $1337 \mathrm{~N} / \mathrm{mm}^{2}$.

\section{B. Justification for design change modified leaf spring}

Stiffness: By analytically and CAE, it is found that existing spring having higher stiffness deteriorate ride of vehicle in unladen condition while modified leaf spring having optimized stiffness along with ride improvement.

Stress Limits: Stresses in modified leaf spring are within limit as mentioned in SAE spring it should be below 1100 $\mathrm{N} / \mathrm{mm} 2$

Weight optimization: Weight reduced in modified leaf spring it helps to improve the fuel economy, unladed weight of vehicle. Improvement in Ride: Lesser-unsprung mass of vehicle help to give good ride and handling of vehicle. Height Ride Improvement: Modified leaf spring designed for softer ride and optimized deflection so that ride height will get reduced it helps minimum rolling of vehicle.

Table I Stress Comparison Of Existing Parabolic Leaf Spring

\begin{tabular}{|c|c|c|c|}
\hline \multicolumn{4}{|c|}{ Existing Leaf Spring } \\
\hline & Analytical & CAE & Experimental \\
\hline Stress N/mm & 1201.4 & 1204.749 & 1227.77 \\
\hline
\end{tabular}




\section{International Advanced Research Journal in Science, Engineering and Technology}

Vol. 5, Issue 10, October 2018

Table II Stress Comparison Of Modified Parabolic Leaf Spring

\begin{tabular}{|c|c|c|}
\hline \multicolumn{3}{|c|}{ Modified Leaf Spring } \\
\hline & Analytical & CAE \\
\hline Stress N/mm & 1012 & 1014 \\
\hline
\end{tabular}

\section{CONCLUSION}

The results are generated by considering the load deflection testing at $65 \mathrm{KN}$ load with the reference SAE spring design manual. Load deflection test concluded that experimental stress value is more than SAE standard design stress. Modified existing leaf spring by using $1150 \mathrm{Kg}$ load and analysis is done in ABAQUS workbench. After the certain modification in design like spring thickness, type of eye, position of friction pad, stack thickness, spacer plates, position of rebound clamp and front clamp, there are minimum stresses at the center flat area in modified leaf spring stress as compared to existing leaf spring. The deflection found by using FEA is nearly same in all the leaves and the maximum deflection is $46.10 \mathrm{~mm}$

\section{REFERENCES}

[1]. Julian Happian-Smith, Butterworth-Heinemann Linacre House, Jordan Hill, Oxford, an Introduction to Modern Vehicle Design, pp. 283 - 311 , 2011

[2]. Jörnsen Reimpell, the Automotive Chassis Engineering Principles, Butterworth-Heinemann Linacre House, Jordan Hill, Oxford PP 23-39, 2010

[3]. Prof. Dr. Giancarlo Genta, the Automotive Chassis Vol.1, Components Design PP 133-207, 2011

[4]. SAEHS788 Manual on Design and Application of Leaf Spring, 2007

[5]. BerndHeißing, MetinErsoy (Eds.), Chassis Handbook, ZF Friedrichshafen AGPP 226-254.

[6]. Bhandari V. B., Design of Machine Elements, Third Edition, McGraw- Hill Publications

[7]. Khurmi, R. S.; Gupta, J. K.; “A textbook of Machine Design” EPH Publication. 1999

[8]. Shiva, Shankar; Vijay Ranjan, S.; "Mono Composite leaf spring for light, end joint analysis and testing".ISSN 1392-1320 Material Science. 2006

[9]. Tavakkoli, Shahriar; "Analytical Prediction of leaf spring bushing loads using MSC/NASTRAN and MDI/ADAMS". Ford Motor 2010

[10]. Ruchik Tank and Srinivas Kurna, Investigation of Stresses and Deflection in Multi Stage Leaf Spring of Heavy Duty Vehicle by FEM and Its Experimental Verification by 2010

\section{BIOGRAPHY}

Sudheer Omprakash Salunke, Industrial Engineering from Indian institution of Industrial Engineering, Pursuing Masters in Mechanical Engineering (CAD ME) from Savitribai Phule University, Pune. 